\title{
Exploration Space Suit Architecture and Destination Environmental-Based Technology Development
}

\author{
Terry R. Hill (NASA’s Lyndon B. Johnson Space Center, Houston, Texas), \\ F. Adam Korona (Jacobs Technology Inc., Houston, Texas) \\ and Shane McFarland (MEI Technologies, Houston)
}

\begin{abstract}
This paper continues forward where EVA Space Suit Architecture: Low Earth Orbit Vs. Moon Vs. Mars [1] left off in the development of a space suit architecture that is modular in design and could be reconfigured prior to launch or during any given mission depending on the tasks or destination. This paper will address the space suit system architecture and technologies required based upon human exploration extravehicular activity (EVA) destinations, and describe how they should evolve to meet the future exploration EVA needs of the US human space flight program.1, 2, 3
\end{abstract}

In looking forward to future US space exploration to a space suit architecture with maximum reuse of technology and functionality across a range of mission profiles and destinations, a series of exercises and analyses have provided a strong indication that the Constellation Program (CxP) space suit architecture is postured to provide a viable solution for future exploration missions4. The destination environmental analysis presented in this paper demonstrates that the modular architecture approach could provide the lowest mass and mission cost for the protection of the crew given any human mission outside of low-Earth orbit (LEO). Additionally, some of the high-level trades presented here provide a review of the environmental and non-environmental design drivers that will become increasingly important the farther away from Earth humans venture.

This paper demonstrates a logical clustering of destination design environments that allows a focused approach to technology prioritization, development, and design that will maximize the return on investment, independent of any particular program, and provide architecture and design solutions for space suit systems in time or ahead of need dates for any particular crewed flight program in the future. The approach to space suit design and interface definition discussion will show how the architecture is very adaptable to programmatic and funding changes with minimal redesign effort such that the modular architecture can be quickly and efficiently honed into a specific mission point solution if required. Additionally, the modular system will allow for specific technology incorporation and upgrade as required with minimal redesign of the system.

1 U.S. Government work not protected by U.S. copyright

2 IEEEAC paper \#1330, originally submitted January 10, 2011, sections have been augmented since that time.

3 This paper was peer reviewed for technical content by: Lindsay Aitchison (Pressure Garment Engineer), Kimberley Baird (Dep.

Branch Manager), Cinda Chullen (EVA Technology Development), B. Michael Lawson (CxP Suit Element Life Support Subsystem

Manager), Joseph J. Kosmo (Space Suit Advanced Development Lead Engineer), Amy Ross (Pressure Garment Development Lead), William Spenny (ISS EMU Engineering Subsystem Manager), Robert Trevino (Space Suit Life Support Technology Development) and Sandra Wagner (EVA Systems Lunar \& Mars dust mitigation) - NASA/JSC Crew \& Thermal Systems Division, Space Suit and Crew Survival System Branch. 